\title{
Michel Porret, Sur la scène du crime. Pratique pénale, enquête et expertises judiciaires (XVIII ${ }^{\mathrm{e}}-\mathrm{XIX}{ }^{\mathrm{e}}$ siècle)
}

\section{Bianca Gai}

\section{(2) OpenEdition}

\section{Journals}

\section{Edizione digitale}

URL: http://journals.openedition.org/studifrancesi/7561

DOI: 10.4000/studifrancesi.7561

ISSN: 2421-5856

\section{Editore}

Rosenberg \& Sellier

\section{Edizione cartacea}

Data di pubblicazione: 1 décembre 2009

Paginazione: 621-622

ISSN: 0039-2944

\section{Notizia bibliografica digitale}

Bianca Gai, «Michel Porret, Sur la scène du crime. Pratique pénale, enquête et expertises judiciaires (xvıl ${ }^{\mathrm{e}-}$ xIx siècle)», Studi Francesi [Online], 159 (LIII | III) | 2009, online dal 30 novembre 2015, consultato il 09 janvier 2021. URL: http://journals.openedition.org/studifrancesi/7561 ; DOI: https://doi.org/10.4000/ studifrancesi.7561

Questo documento è stato generato automaticamente il 9 janvier 2021.

\section{(†) $\odot$

Studi Francesi è distribuita con Licenza Creative Commons Attribuzione - Non commerciale - Non opere derivate 4.0 Internazionale. 


\title{
Michel Porret, Sur la scène du crime. Pratique pénale, enquête et expertises judiciaires (XVIII ${ }^{\mathrm{e}}$ XIX $\mathrm{X}^{\mathrm{e}}$ siècle)
}

\author{
Bianca Gai
}

\section{NOTIZIA}

MICHEL PORRET, Sur la scène du crime. Pratique pénale, enquête et expertises judiciaires (XVIII ${ }^{e}$ XIX siècle), Montréal, Les Presses de l'Université de Montréal, 2008, pp. 272.

1 Nel XVIII secolo, la riflessione giuridica occupa un ruolo di primo piano all'interno della teorizzazione dell'Illuminismo: l'Esprit des lois di Montesquieu, il trattato Dei delitti e delle pene di Beccaria, l'utilitarismo di Bentham aspirano ad un rinnovamento sociale basato sulla riforma della giustizia. A partire da tali presupposti filosofici, si assiste al passaggio da un esercizio arbitrario del potere giudiziario ad una legalità motivata razionalmente, che si fonda su una concezione secolarizzata del diritto di punire. La Repubblica di Ginevra è il laboratorio delle trasformazioni di cui il saggio rende testimonianza, lasciando emergere dagli archivi ginevrini d'Ancien Régime, racconti ed esperienze del crimine che coinvolgono non solo i detentori e i teorici della giustizia ma anche i suoi soggetti e le sue vittime. La modernizzazione della giustizia criminale è legata all'alleanza della prassi giudiziaria con un sistema di investigazione incentrato sulla perizia scientifica: esperti di varie discipline sono chiamati a illustrare le circostanze e le modalità del crimine, contribuendo alla moderazione delle pratiche penali. Anche in virtù dell'orientamento sempre più scientifico dell'inchiesta variano, insieme alle mentalità, le concezioni e le tipologie delle azioni criminali.

2 La sezione centrale della monografia ricostruisce gli scenari della censura libraria, soffermandosi sui meccanismi di indagine delle autorità di controllo della produzione editoriale e sui rituali di censura delle opere illecite. Paradossali cerimonie di distruzione pubblica, che invece di affievolire potenziano le curiosità del pubblico, sono 
riservate al libro sedizioso. Sottoposto invece a eliminazione immediata fin dal momento della perquisizione, spesso notturna, è il libro osceno. Anche nel caso della polizia libraria, prende il sopravvento sulla valutazione arbitraria del giudice la ricognizione delle istanze materiali dell'oggetto incriminato da parte di uno sguardo esperto: nasce la figura del "détective du livre" (p. 109) che risale all'origine e ai modi di creazione e diffusione delle pubblicazioni clandestine mediante l'analisi delle loro caratteristiche tipografiche.

Insieme al paradigma indiziario, la volontà di definizione analitica delle condizioni del delitto introduce, con l'inaugurazione della medicina legale, il paradigma medicogiudiziario, che costituisce il fulcro d'analisi dell'ultima parte del libro: le tracce del crimine trovano materializzazione e giustificazione scientifica sul corpo violato. Presiede all'esame della scena del crimine e del corpo della vittima una complessa fenomenologia della violenza sessuale. L'analisi medico-legale si esercita anche nei casi di suicidio, gesto che inficiando la solidità sociale e culturale della comunità viene punito con l'esercizio dell'infamia postuma sul cadavere (iniziando a essere considerato solo a partire dal 1740 , a Ginevra, non un reato punibile pubblicamente, ma la conseguenza privata di un dramma individuale). La documentazione inerente agli atti di suicidio - specie le ultime memorie del defunto - restituisce un panorama variegato e toccante di vicende interiori. Altro ruolo che viene ad affiancare l'inchiesta è infine quello del "topographe judiciaire" (p. 225), che procede alla mappatura della scena del delitto: la tendenza all'oggettivazione delle circostanze materiali del crimine include nel sistema probatorio una dettagliata definizione topografica dei luoghi in cui si è verificato l'evento criminale. 